\title{
Inactivation of Pseudomonas aeruginosa in mineral water by DP1 bacteriophage immobilized on ethylene-vinyl acetate copolymer used as seal caps of plastic bottles
}

\author{
Júnia Novello $^{1,2}$ | Sanna Sillankorva ${ }^{3}$ | Priscila Pires $^{4}$ | Joana Azeredo ${ }^{4}$ | \\ César Henrique Wanke $^{1}$ | Eduardo César Tondo ${ }^{2}$ | Otávio Bianchi ${ }^{1,5}$ ()
}

\author{
${ }^{1}$ Exact Sciences and Engineering \\ Knowledge Area, University of Caxias do \\ Sul, Caxias do Sul, Brazil \\ ${ }^{2}$ Institute of Food Science and \\ Technology, Federal University of Rio \\ Grande do Sul, Porto Alegre, Brazil \\ ${ }^{3}$ INL - International Iberian \\ Nanotechnology Laboratory, Av. Mestre \\ José Veiga, Braga, Portugal \\ ${ }^{4}$ Center of Biological Engineering, \\ University of Minho, Braga, Portugal \\ ${ }^{5}$ Department of Materials Engineering, \\ Federal University of Rio Grande do Sul, \\ Porto Alegre, Brazil

\section{Correspondence} \\ Júnia Novello and Otávio Bianchi, Exact \\ Sciences and Engineering Knowledge \\ Area, University of Caxias do Sul, \\ Francisco Getúlio Vargas Road, 1130, \\ 95070-560, Caxias do Sul, Rio Grande do \\ Sul, Brazil. \\ Email: jclnovello@ucs.br (J.N.) and \\ otavio.bianch@gmail.com (O.B.) \\ Funding information \\ National Council for Scientific and \\ Technological Development, Grant/Award \\ Numbers: 306086/2018-2, 308241/2015-0; \\ European Union's Horizon 2020 research \\ and innovation programme, Grant/Award \\ Number: 713640
}

\begin{abstract}
Pseudomonas aeruginosa has been found in bottled natural mineral water, even though its presence is not allowed in this product by different food regulations. This study aimed to investigate the inactivation of $P$. aeruginosa present in mineral water by vB_PaeM_CEB_DP1 (short name DP1) bacteriophage immobilized on ethylene-vinyl acetate (EVA) copolymer used as seal caps of plastic bottles. EVA was chemically modified using microwave-assisted alcoholysis, improving polymer-phage binding. After that, DP1 phage was attached to EVA and EVA-OH copolymers and both surfaces were tested for plaque formation using $P$. aeruginosa. Then, both materials containing immobilized phages were used as seal caps of plastic bottles and its antimicrobial capacity was tested against $P$. aeruginosa contaminating mineral water. The EVA-OH resulted in higher hydrogen bond density that contributed significantly to the phage immobilization on the polymer surface. The polymers containing immobilized phages were able to reduce $0.53 \log$ of $P$. aeruginosa population present inside mineral water bottles after 14 days.
\end{abstract}

\section{K E Y W O R D S}

applications, functionalization of polymers, packaging

\section{1 | INTRODUCTION}

During the last years, the consumption of natural mineral water has increased worldwide, mainly because consumers are more concerned about the increasing water contamination, the successful marketing strategies of the bottling companies, and the frequent chlorine taste and odor of tap waters supplied by municipal bodies. ${ }^{[1]}$ Beyond that, chlorine and chloramine used to the treatment of public water may react with organic matter dissolved in the water, forming cytotoxic products, such as halamines, haloacetamides, halonitriles, and heterocyclic amines. ${ }^{[2,3]}$

Natural mineral waters are not sterile and complex bacterial ecosystems with high phenotypic and genotypic diversity may be present. ${ }^{[4]}$ The bacterial load of bottled mineral water is dependent on the quality of natural 
spring-water and on the good hygienic practices carried out inside industrial facilities. Microorganisms can be present on the surfaces of pumps, pipes, caps, and bottles ${ }^{[3]}$ resulting in the contamination of end products. Bacterial counts of bottled mineral water can reach values ranging from $10^{4}$ to $10^{5}$ colony forming units (CFU) per $\mathrm{ml}$ after some days of storage ${ }^{[5]}$; however, pathogens are not expected to be present.

According to the Brazilian regulation and international directives, ${ }^{[6,7]}$ mineral water for human consumption has to be free of Pseudomonas aeruginosa. ${ }^{[4]}$ This microorganism can be found in different natural and aqueous environments, being possible to contaminate mineral water during bottling process. ${ }^{[8]}$ Pseudomonas aeruginosa is an opportunistic human pathogen that has been associated with some waterborne disease cases and frequent nosocomial-acquired outbreaks. ${ }^{[9]}$ This bacterium can cause chronic persistent infections and form biofilms on different surfaces, becoming resistant to antimicrobial therapy, host immune response ${ }^{[10]}$ and sanitizers.

Pseudomonas aeruginosa can contaminate water and other fluids, such as milk in feeding bottles, and cause outbreaks. ${ }^{[4]}$ According to Rosenberg and HemandezDuquino, ${ }^{[8]}$ Pseudomonas adhesion on plastic bottle surfaces generally reaches higher numbers than on glass bottle surfaces. One hypothesis for this finding is the permeability of the external plastic vapors, for example, oxygen, which consequently enhances survival and microbial growth. Beyond that, the rapid microbial growth after filling may also be related to oxygenation of mineral water, temperature rise during the storage, and the small number of nutrients present on package surfaces. $^{[11]}$

Bacteriophages (phages) were successfully used for the first time to treat bacterial infections a decade before the discovery of penicillin. They are not pathogenic for man, and they are particularly efficient for their target bacteria. Initially, the phage injects its nucleic acid into the bacteria and then these do DNA copies. After that, they make and package more of phages into new structures. Lastly, the phages produce toxic chemicals that rupture the bacterial host, releasing its new virus to the outside. $^{[12]}$

Recently, phages have emerged as a new approach to control bacterial contamination in food industries, ${ }^{[13]}$ particularly in animal husbandry, horticulture, and agriculture. ${ }^{[14]}$ As examples, the products ListShield and EcoShield are made up of bacteriophages and are sold to control Listeria and Escherichia coli O157, respectively, while LISTEXTM P100 is a GRAS (generally recognized as safe) product available for use in food. ${ }^{[13,15]}$
Several companies worldwide are using bacteriophages to control bacterial contamination. Pearson et al. ${ }^{[16]}$ anchored E. coli and Staphylococcus aureus phages on polyethylene (PE) and polytetrafluoroethylene (PTFE) surfaces and were able to reduce bacterial counts and biofilms. Wang et al. immobilized phage T4 on the polyhydroxyalkanoate (PHA) surfaces and the infective capability of attached phages was tested exposing the phage-immobilized surfaces to $E$. coli. In both studies, ${ }^{[16,17]}$ the formation of specific chemical bonds between polymer-phage was essential for the increase of the phage binding on the surface of the polymers.

Several approaches have been employed in the immobilization of phages in polymers bulk or surfaces. ${ }^{[16,18,19]}$ Encapsulation of phages in solvent-emulsion microspheres may result in loss of phage activity due to the organic solvent employed. ${ }^{[20]}$ The creation of antimicrobial surfaces with covalent bonding or by electrostatic interactions between polymer-phage, taking advantage of the different charge distribution between head and tail, seems like a promising strategy. ${ }^{[16,18]}$ A limitation of these approaches is to use systems that are already in production scale since they use chemical reagents that can contribute to reduced product integrity. In the case of drinking water, contamination with small amounts of organic solvents can render a valuable asset unusable. ${ }^{[21]}$ Thus, cleaner approaches to products that are already in use can directly contribute to the advance of phage use.

These approaches cannot use systems that are already in production scale, as they use chemical reagents that can contribute to the reduction of product integrity. In the case of drinking water, contamination with small amounts of organic solvents can render a valuable commodity useless. Thus, cleaner approaches to products that are already in use can directly contribute to the advancement of phage use.

The FDA regulates the ethylene-vinyl acetate (EVA)vinyl alcohol (VOH) copolymer for direct contact with food. The partial or complete alcoholysis or hydrolysis of EVA copolymers complying complies with section 177.1350 of the FDA regulamentations. ${ }^{[22]}$ EVA copolymers have low cytotoxicity ${ }^{[23,24]}$ and have been used as a medical device construction proposal due to its chemical resistance, toughness, clarity, and color stability. Ethylene copolymers are derived from ethylene and another compound with a polar functional group such as $\mathrm{VOH}$, vinyl acetate (VA) are the most frequently used food-packaging polymers. However, EVOH or EVA-OH has the most promising gas-barrier properties due to better chain packing aided by hydrogen bonds. ${ }^{[25,26]}$

The objective of the present study was to immobilize DP1 phages on the surfaces of EVA used as seal caps of 
plastic bottles for mineral water. We also investigated the samples of EVA and EVA-OH produced by microwaveassisted alcoholysis, aiming to understand how chemical interaction occurs between the polymer groups and phages and its capacity to eliminate $P$. aeruginosa in mineral water. Therefore, polymer seal caps with immobilized DP1 phages can be a strategy to contribute with the control of $P$. aeruginosa contamination of bottled mineral water.

\section{2 | EXPERIMENTAL}

\section{1 | EVA films: Preparation and characterizations}

EVA copolymer (Braskem, HM 728, Triunfo, Brazil) with $28 \mathrm{wt} \%$ of VA content and melt flow index $\left(190^{\circ} \mathrm{C} / 2.16 \mathrm{~kg}\right)$ of $6.0 \mathrm{~g} / 10 \mathrm{~min}$, average molecular weight of $M_{\mathrm{n}}=146,000 \mathrm{~g} / \mathrm{mol}$, and polydispersity index of $M_{\mathrm{w}} / M_{\mathrm{n}}=3.2$ determined by thermogravimetry and gel permeation chromatography measurements were used in this study. EVA copolymer was chemically modified by alcoholysis reaction and was produced according to the procedure described by Paradinha et al. ${ }^{[26]}$ in order to improve the polymer/phage compatibility.

EVA pellets $(26 \mathrm{~g})$ were solubilized in Tetrahydrofuran (THF, ACS grade-VETEC, Xerém, Brazil) (104 g at $45^{\circ} \mathrm{C}$ ) and placed into a $250-\mathrm{ml}$ three-necked flask equipped with a reflux condenser. Then, $60 \mathrm{ml}$ of $0.5 \mathrm{M}$ alcoholic sodium hydroxide $(\mathrm{NaOH}, \mathrm{ACS}, 97 \%$ of purity, VETEC, Xerém, Brazil) were added into the EVA/THF solution and the medium was microwave refluxed for $30 \mathrm{~min}$.

After the alcoholysis reactions, EVA was neutralized with $10 \mathrm{ml}$ solution of $3 \mathrm{M}$ hydrogen chloride ( $\mathrm{HCl}$, ACS Grade, VETEC, Xerém, Brazil). Then, the samples were washed using boiled ultrapure water (Milli-Q) to remove the alcoholysis products such as sodium acetate. The degree of chemical modification of EVA was determined using ${ }^{1} \mathrm{H}$ NMR (Bruker Fourier $300 \mathrm{Mhz}$ in $\mathrm{CDCl}_{3}$ at $25^{\circ} \mathrm{C}$ ) and ATR-FTIR (PerkinElmer, Spectrum 400 equipped with an attenuated total reflectance ATR diamond crystal at $45^{\circ}$, resolution of $2 \mathrm{~cm}^{-1}$, 32 scans from 4,000 to $500 \mathrm{~cm}^{-1}$ ) (see Supporting Information). The immobilization of the phages and subsequent characterizations of the EVA and EVA-OH samples were done on films produced by compression molding at $160^{\circ} \mathrm{C}$ and $6 \mathrm{MPa}$ ( $2 \mathrm{~min}$ ). The contact angle measurements were made using sessile drop technique (DSA 30/Krüss, Germany). The contact angle values were computed using Surftens 3.0TM software (Frankfurt, Germany).
This technique was performed to evaluate the polarity change after the chemical modification of the EVA by alcoholysis reaction. For this, 10 drops of deionized water and $n$-hexadecane were placed on different parts of EVA surface films $\left(60 \times 25 \mathrm{~mm}^{2}\right)$. The contact angle was measured on each side of the surface, totalizing 10 measurements for each liquid. The highest and lowest values were discarded. The arithmetic mean and the standard deviation were, respectively, the mean value and the error measurement. The contact angles of the surfaces of the films that characterized the wettability were analyzed according to the literature, ${ }^{[27]}$ in which the surfaces were classified as hydrophilic (contact angle with water less than $90^{\circ}$ ) or hydrophobic (contact angle with water between $91^{\circ}$ and $150^{\circ}$ ) and superhydrophobic (contact angle with water greater than $151^{\circ}$ ). Besides, the free energy of the surfaces was estimated according to Owens and Wendt. ${ }^{[28]}$

\section{2 | Bacterial strains and culture preservation conditions}

The microbiological assays were performed using $P$. aeruginosa strain PAO1 isolated from an endoscope (Rouen, France). Phage vB_PaeM_CEB_DP1 (short name DP1) used in this study was isolated from the hospital effluents of the Hospital de São João (Porto, Portugal). ${ }^{[29]}$

Pseudomonas aeruginosa strain PAO1 was cryopreserved at $-80^{\circ} \mathrm{C}$ in Tryptone Soya Broth (TSB) with $30 \%$ (v/v) of glycerol (AppliChem, Germany), and DP1 Phage was kept at $4^{\circ} \mathrm{C}$ in buffer saline magnesium (SM buffer; $5.8 \mathrm{~g} / \mathrm{L} \mathrm{NaCl}, 2 \mathrm{~g} / \mathrm{L} \mathrm{MgSO}_{4} .7 \mathrm{H}_{2} \mathrm{O}, 50 \mathrm{ml}$ of $1 \mathrm{M}$ Tris- $\mathrm{HCl}$ [pH 7.5]) (Applichem, Germany).

\section{3 | Bacteriophage production}

Phages were produced using the protocol described by Pires et al. ${ }^{[29]}$ First, bacterial lawns were prepared, pouring $0.1 \mathrm{ml}$ of overnight-grown $P$. aeruginosa suspension using the pour plate technique. After drying, plates were added with $3 \mathrm{ml}$ of top-agar (TSB $+0.6 \%[\mathrm{w} / \mathrm{v}]$ agar). Then, sterile paper $\left(80 \mathrm{~g} / \mathrm{m}^{2}\right)$ strip rectangles $(1 \mathrm{~cm}$ per $5 \mathrm{~cm}$ ) were immersed in the phage stock solution and streaked on the bacterial lawns. The plates were incubated from 16 to $18 \mathrm{~h}$ at $25^{\circ} \mathrm{C}$ and then $3 \mathrm{ml}$ of SM buffer was added. The plates were placed under agitation (120 rpm) at $4^{\circ} \mathrm{C}$ during $16-18 \mathrm{~h}$ and, afterward, the liquid phase and top-agar (TSB, $0.6 \%[\mathrm{w} / \mathrm{v}]$ agar) layer were collected, centrifuged, and the supernatant was filtered (0.2 $\mu \mathrm{m}$ MilliporeSigma, Germany). 


\subsection{Phage attachment on EVA and EVA-OH surfaces}

The DP1 phage immobilization on EVA and EVA-OH surfaces was performed according to the protocol described by Pearson et al., with some modifications. ${ }^{[16]}$ The assays were performed on sterile 24-well plates (flatbottomed uncoated polystyrene tissue culture plates, Orange Scientific, Belgium). EVA and EVA-OH films were placed into each well and $1,000 \mu$ l of phosphatebuffered saline (PBS) buffer $(0.1 \mathrm{~mol} / \mathrm{l}, \mathrm{pH} 7.4$, HiMedia, India), containing $2.5 \mathrm{mmol}$ of 1-ethyl-3-(3-dimethylaminopropyl) carbodiimide (Sigma-Aldrich, Germany) and $2.5 \mathrm{mmol} \mathrm{N}$-hydroxysuccinimide (Sigma-Aldrich, Germany) were added for $2 \mathrm{~h}$ in order to create - COOgroups followed by washing with PBS. Then, the coupons were immediately immersed into $10 \mathrm{ml}$ buffer solution containing $500 \mu \mathrm{l}$ of concentrated phage for $16 \mathrm{~h}$. After that, the coupons were washed seven times in $15 \mathrm{ml}$ PBS buffer in order to remove all nonbonded phages. ATRFTIR monitored the presence of phages on EVA surfaces.

\section{5 | Plaque formation assay for the phage immobilized on surfaces}

The films containing attached bacteriophages were used for the plaque formation assay as described in Reference [16] with some modifications. Pseudomonas aeruginosa was subcultured on Trytone Soya Agar (TSA; HiMedia, India) at $37^{\circ} \mathrm{C}$ for $24 \mathrm{~h}$. After that, colonies were inoculated into $15 \mathrm{ml}$ of TSB at $37^{\circ} \mathrm{C}$ for $18 \mathrm{~h}$, at $90 \mathrm{rpm}$. An amount of $100 \mu \mathrm{l}$ of cell suspension (8.0 $\log \mathrm{CFU} / \mathrm{ml}$ ) was spread on Petri plates containing TSA using a swab and, after $10 \mathrm{~min}$, the coupons with attached and nonattached-phage $\left(1 \times 1 \quad \mathrm{~cm}^{2}\right)$ were stabbed on the agar into Petri plates. The plates were incubated at $37^{\circ} \mathrm{C}$ for $24 \mathrm{~h}$, and the formation of clear plaques around the surfaces was observed and counted. Images were taken to record the plaques produced by phages.

\subsection{Antimicrobial activity in mineral water bottles}

Commercial $500 \mathrm{ml}( \pm 20 \mathrm{ml})$ bottles of mineral water were purchased in a local market of Porto Alegre city, Southern Brazil. The composition of mineral water was as follows: $\mathrm{pH} 7.1$, bicarbonate $122.64 \mathrm{mg} / \mathrm{l}$, calcium $24.10 \mathrm{mg} / \mathrm{l}$, chloride $1.22 \mathrm{mg} / \mathrm{l}$, fluoride $0.19 \mathrm{mg} / \mathrm{l}$, lithium $0.011 \mathrm{mg} / \mathrm{l}$, magnesium $2.75 \mathrm{mg} / \mathrm{l}$, potassium $1.93 \mathrm{mg} / \mathrm{l}$, sodium $14.74 \mathrm{mg} / \mathrm{l}$.
Neutral liquid soap (Kalykim, Brazil) was used to wash the external side of bottles, which were dried using paper towels and sanitized with 70\% ethylic alcohol $[\mathrm{v} / \mathrm{v}]$. A volume of $5 \mathrm{ml}$ of mineral water was removed from each bottle. Then, $5 \mathrm{ml}$ of the sterile mineral water containing $P$. aeruginosa was added, reaching a final concentration of $10^{4} \mathrm{CFU} / \mathrm{ml}$ into each of the three bottles used for each of the following treatments. EVA copolymer seals with and without attached DP1 phage were placed into three sets of three bottle caps $(\mathrm{MOI}=1)$. After that, the bottles with $P$. aeruginosa were closed and incubated at $25^{\circ} \mathrm{C}$ upside down without agitation. Pseudomonas aeruginosa and DP1 phages counts were carried out just after inoculation and then after 1, 7, and 14 days, using Cetrimide Agar Base plates (HiMedia, India), incubated at $35^{\circ} \mathrm{C}$ for $48 \mathrm{~h}$. The difference between the initial and final bacteria or phage count was expressed in $\mathrm{CFU} / \mathrm{ml}$, and the results of plaque counts were expressed in $\mathrm{PFU} / \mathrm{ml}$, respectively.

Water bottles without the seal polymers and without $P$. aeruginosa were used as negative controls. All the counts were carried out in triplicates, and the experiment was independently repeated three times.

\section{3 | RESULTS AND DISCUSSION}

The NMR spectra (Supporting Information) showed at $\delta=2.05$ and $4.88 \mathrm{ppm}(\alpha-\mathrm{H})$. The EVA spectra had a characteristic peak due to methyl and methine protons of the VA. ${ }^{[30,31]}$ A broad peak at 1.4-1.7 ppm, corresponding to the $\beta$-H was observed $\left(\mathrm{CH}_{2}\right.$ in VA segment). The methyl and methine protons and other signals in the chemical modified sample (EVA-OH) were the same found in pure EVA. The regions between 1.4 and $1.7 \mathrm{ppm}$ showed the signal for $\mathrm{CH}_{2}$ in VA and $\mathrm{OH}$ segments $(\beta-\mathrm{H})$. The peak at $\delta=3.76 \mathrm{ppm}$ observed in EVA-OH was characteristic of the hydroxyls groups generated by alcoholysis reactions. $^{[26]}$

FTIR spectrum of EVA and EVA-OH samples (showed in Supporting Information) demonstrated the characteristics bands of $\mathrm{C}=\mathrm{O}$ stretching relative to ester carbonyl group (at $1738 \mathrm{~cm}^{-1}$ ), $\mathrm{C}-\mathrm{O}$ stretching at $1,240 \mathrm{~cm}^{-1}$, and symmetric stretching vibration of $\mathrm{C}-\mathrm{O}-\mathrm{C}$ band at $1,016 \mathrm{~cm}^{-1}$ related to the VA group in copolymer. ${ }^{[26,32]}$ The $\mathrm{CH}_{2}$ stretching band at $2,920 \mathrm{~cm}^{-1}$, $\mathrm{CH}_{2}$ deformation band at $1,370 \mathrm{~cm}^{-1}$, and $\mathrm{CH}_{2}$ scissoring band at $14,65 \mathrm{~cm}^{-1}$ were observed. After hydrolysis, the appearance of two new bands was noted. One related to the $\mathrm{VOH}(\mathrm{C}-\mathrm{O})$ at $1,280 \mathrm{~cm}^{-1}$ and other related to the $-\mathrm{OH}$ stretching at $3,080-3,700 \mathrm{~cm}^{-1}$, from the intermolecular hydrogen bond, because of the $\mathrm{VOH}$ group. The hydroxyls and carboxylate groups were possibly 
FI G URE 1 FTIR spectra $\mathrm{OH}$ $\left(4,000-3,000 \mathrm{~cm}^{-1}\right)$ and $\mathrm{C}=\mathrm{O}$ $\left(1,800-1,650 \mathrm{~cm}^{-1}\right)$ regions. $\mathrm{C}=\mathrm{O}$ region was fitted using Voigt functions $(R>0.994)$ [Color figure can be viewed at wileyonlinelibrary.com]

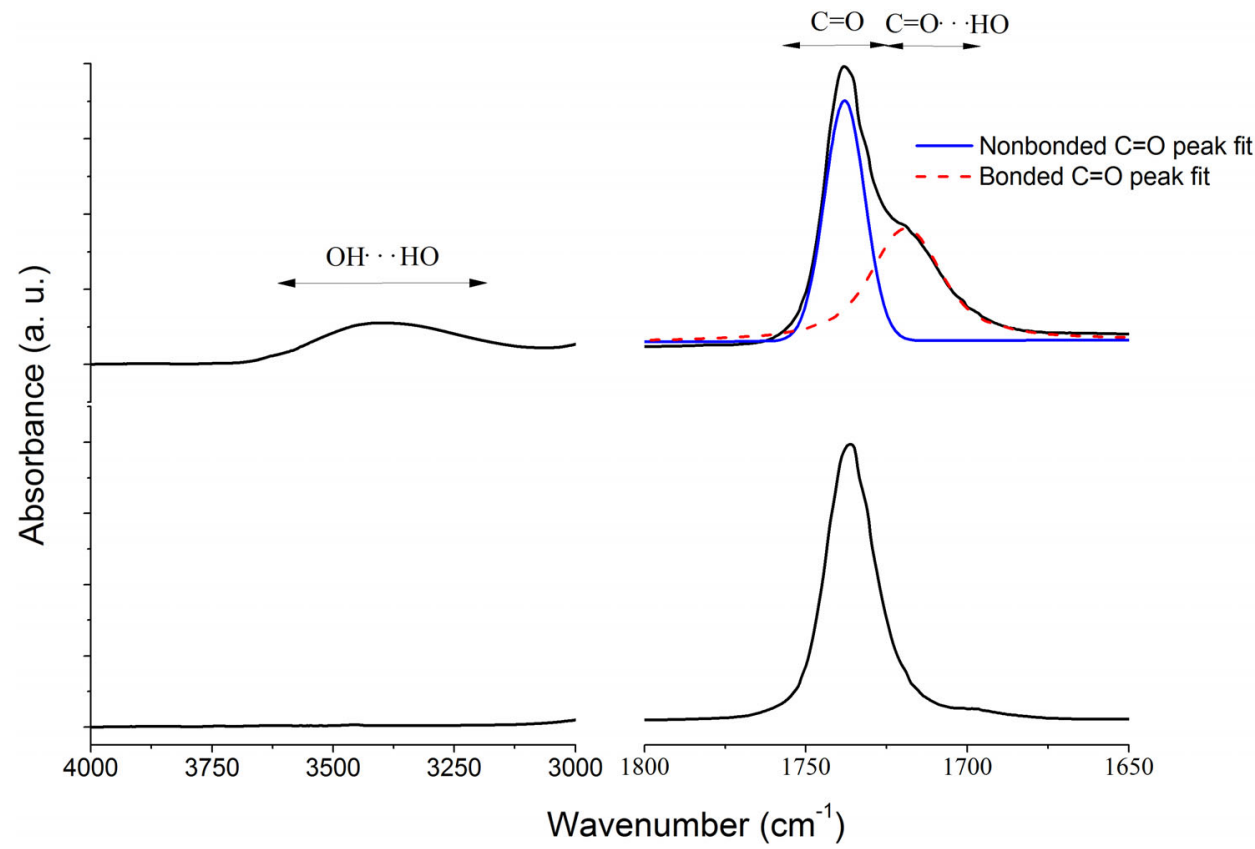

TABLE 1 Surface properties of EVA and EVA-OH copolymers

\begin{tabular}{|c|c|c|c|c|c|}
\hline \multirow[b]{2}{*}{ Sample } & \multicolumn{2}{|c|}{ Contact angle (degree) } & \multicolumn{3}{|c|}{ Surface energy $\left(\mathrm{mJ} / \mathrm{m}^{2}\right)$} \\
\hline & Water & $n$-hexadecane & Polar & Dispersive & Total \\
\hline EVA & $86.4 \pm 1.7$ & $25.3 \pm 1.6$ & $25.0 \pm 0.3$ & $0.5 \pm 0.4$ & $25.5 \pm 0.4$ \\
\hline EVA-OH & $81.0 \pm 2.5$ & $15.0 \pm 1.8$ & $26.7 \pm 0.2$ & $1.4 \pm 0.7$ & $27.2 \pm 0.6$ \\
\hline
\end{tabular}

responsible for the immobilization of the phage on the polymer surface. Figure 1 shows FTIR spectra for the region of the $\mathrm{OH}$ and $\mathrm{C}=\mathrm{O}$ groups for EVA and EVA$\mathrm{OH}$. In these regions, it is possible to identify the effect generated from the alcoholysis reaction. The NMR and FTIR results confirmed that part of the acetate groups was converted into hydroxyl groups after alcoholysis reaction. As a result of the partial alcoholysis reaction, there was a formation of $\mathrm{HO} \cdots \mathrm{HO}$ and $\mathrm{C}=\mathrm{O} \cdots \mathrm{HO}$. The alcoholysis degree estimated by NMR was $\sim 42.6 \%$.

It was observed that the surfaces of the polymers used are hydrophilic and have an angle of contact with water $\left(\theta_{\mathrm{w}}\right)$ was less than $90^{\circ} .{ }^{[28]}$ EVA-OH was the most hydrophilic surface $\left(\theta_{\mathrm{w}}=80 \pm 3^{\circ}\right)$ (Table 1). Thus, by the nature of DP1 phages, which has peptide bonds, it should increase the phage and EVA-OH surface interactions and thus remains more strongly linked when compared to the pure EVA. As well as the contact angle, there was also the variation of the surface energy components for EVA$\mathrm{OH}$. As expected, EVA-OH polarity was higher $\left(26.7 \mathrm{~mJ} / \mathrm{m}^{2}\right)$ than pure EVA. Thus, the increase in hydrophilicity favors the immobilization of the phage by specific interactions. ${ }^{[16,17]}$

Pearson et al. also verified the presence of carboxyl $(-\mathrm{COOH})$ and hydroxyl $(-\mathrm{OH})$ groups after the modification of PE and PTFE surfaces with maleic anhydride. ${ }^{[16]}$ Moreover, these two groups are responsible for the immobilization of the phage T4 onto PHA surfaces. ${ }^{[17]}$

FTIR was used to verify the attachment of DP1 phage to the surface of the polymers (Figure 2a). A band at $1,640 \mathrm{~cm}^{-1}$, relative to the primary amide, was observed for both polymers and phage systems. ${ }^{[33]}$ However, for pure EVA, a lower intensity was observed, which is indicative of the smaller amount of the phage bonded, also noted in the region of $3,700-3,060 \mathrm{~cm}^{-1}$. The difference in intensity was due to the formation of interactions $-\mathrm{NH}$... OH- by hydrogen bonds. Through the mathematical deconvolution of the area in the $\mathrm{C}=\mathrm{O}$ region $\left(1,738 \mathrm{~cm}^{-1}\right)$, it was possible to estimate the relative amount of hydrogen bonding in the carbonyl group. EVA-OH without phages showed the relative index of 0.52, whereas for the EVA-OH with phages demonstrated 0.41 . Therefore, it is possible to infer that the phage also associates through interactions $\mathrm{NH} \cdots \mathrm{OH}$, which suggests that the association phage-EVA-OH also occurs through multiple hydrogen bonds. Concerning the EVA, the $\mathrm{C}=\mathrm{O}$ group limits the formation of specific interactions when compared to EVA-OH. Consequently, the relative index of hydrogen bonding in the carbonyl group for pure 

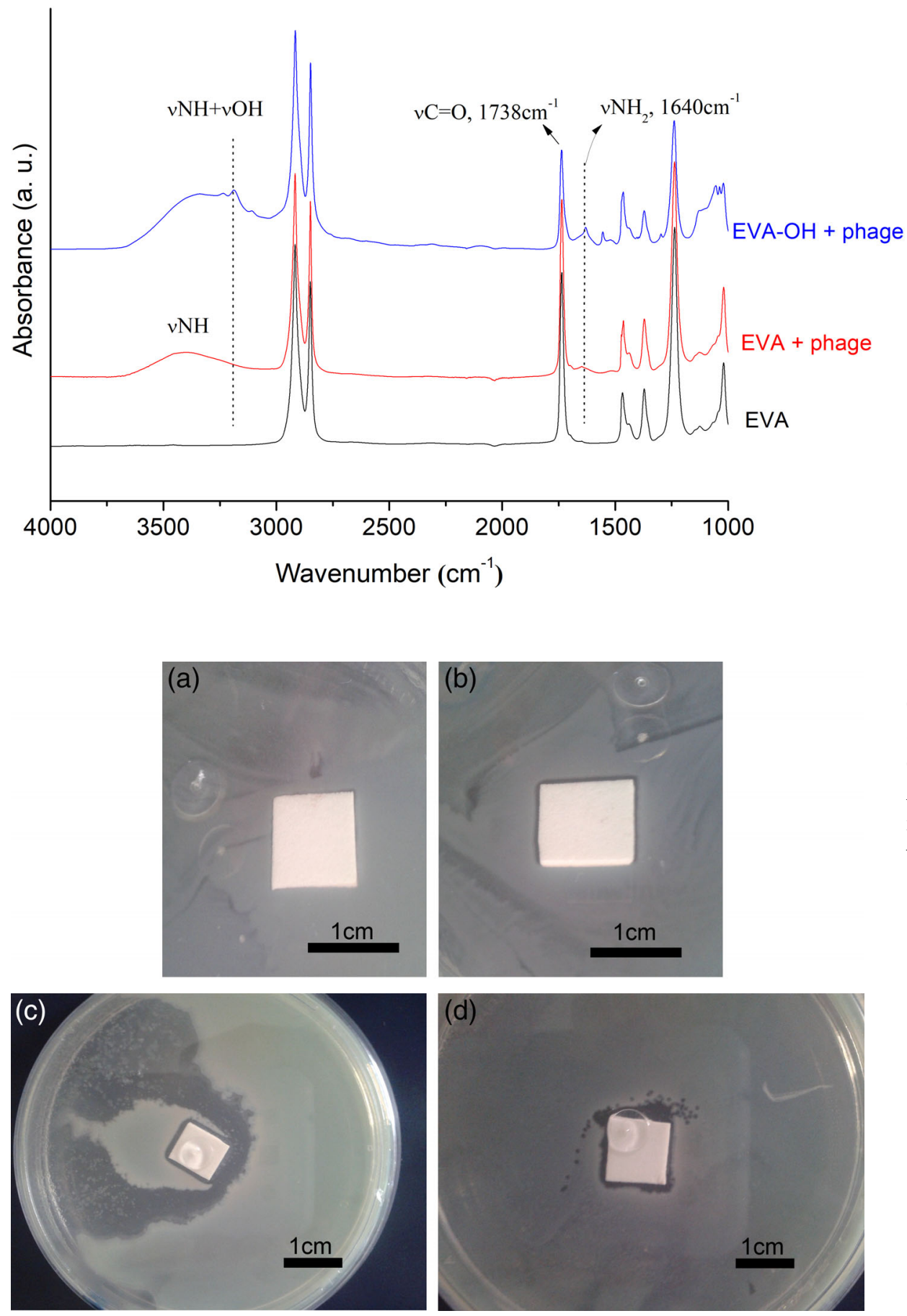

FIG URE 2 FTIR spectra of EVA and EVA-OH with attached DP1 phage. Absorbance intensity shows the increase of the peptide bond interactions between phage and polymers [Color figure can be viewed at wileyonlinelibrary.com]
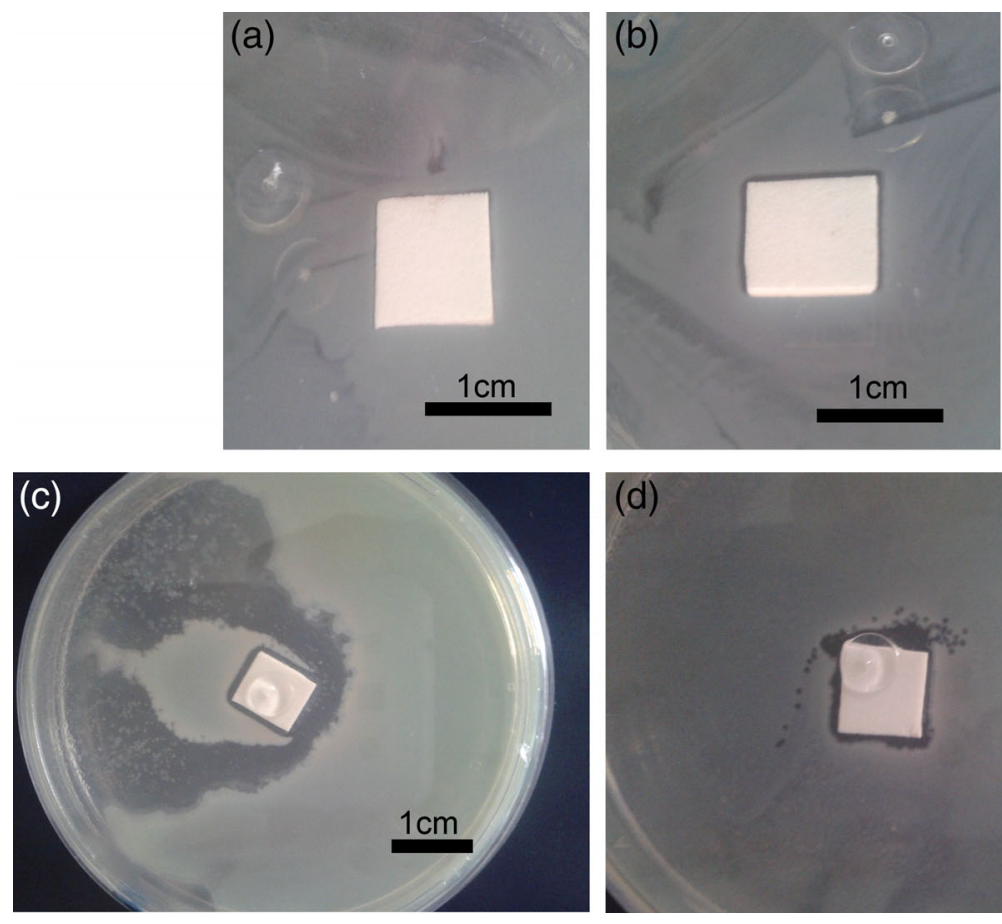

EVA/phase is lower than the EVA-OH, demonstrating the value of 0.14 .

According to Figure $3 \mathrm{a}, \mathrm{b}$, it was possible to verify a transparent halo (lysis plaques) formed around the polymers with the immobilized phage. This result demonstrated that the EVA surfaces were able to inactivate $P$. aeruginosa, as a result of the phage activity.

As the incubation time increased, the size of plaques increased too. Moreover, the plaques did not occur in control coupons (positive and negative controls) (Figure 3a,b). Similar results were demonstrated by Pearson et al., ${ }^{[16]}$ who immobilized T1 bacteriophages on PE and PTFE surfaces which were able to inactivate $S$. aureus and $E$. coli. The use of EVA-OH for the phage attaching is interesting because it is less toxic than EVA and produces a more efficient barrier for gases than other olefinic polymers. ${ }^{[34]}$ So, a similar approach could be used to immobilize specific bacteriophages on the surfaces of EVA used as bottle cap seals in order to control $P$. aeruginosa in natural mineral waters, and this was done in the present study.
F I G URE 3 Transparent halos (plaque formation assays) on (a) positive and (b) negative controls, (c) EVA and (d) EVA-OH with DP1 phages against $P$. aeruginosa in water bottles [Color figure can be viewed at wileyonlinelibrary.com] 


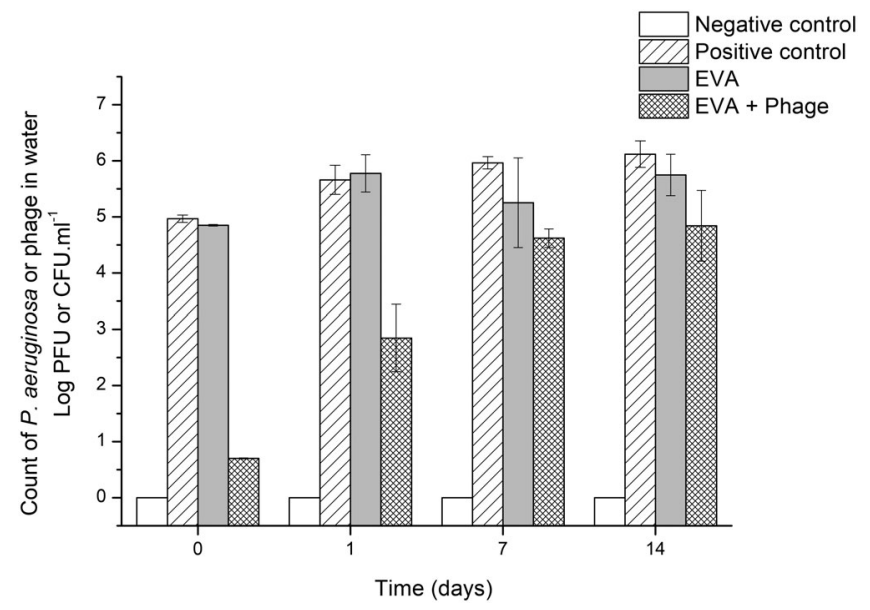

F I G U RE 4 Pseudomonas aeruginosa $(\log \mathrm{CFU} / \mathrm{ml})$ and DP1 bacteriophages $(\log \mathrm{PFU} / \mathrm{ml})$ counts after $0,1,7$, and 14 days of assay, carried out for testing the anti-P. aeruginosa activity of EVA polymers used as cap seal containing immobilized DP1 phages inside mineral water bottles. Containing the virus ("Bottle with EVA"), without the virus but with the bacteria ("Positive control bottle"), and without the virus and bacteria ("Negative control bottle")

It was observed that the numbers of DP1 phages increased inside mineral water bottles until 14 days ( 5 or $6 \log$ PFU/ml). Furthermore, there was a less plaqueforming unit (4.8 $\log \mathrm{PFU} / \mathrm{ml})$ inside bottles with EVA (Figures 4 and 5) when compared to bottles with EVA$\mathrm{OH}$, indicating that the higher concentration of polar groups resulted in greater immobilization of phages through peptide bonds. ${ }^{[16,17]}$

Nonetheless, it was observed that the most significant bacterial reduction ( $0.53 \log$ reduction) occurred at 14 days in the mineral water bottles containing EVA polymer with DP1 phages (Figure 4). Despite the antimicrobial effectiveness of the DP1 phage against $P$. aeruginosa cells, the phages were not able to eliminate all microorganisms. It is possible that the agitation of bottles could result in better reduction levels, simulating what happens during mineral water bottle transport. We decided to carry out this test without agitation aiming to access the worst scenario.

Antibiotic treatment is currently the most widely used therapy for $P$. aeruginosa infections. However, over the past few years, this bacterium has grown impervious toward several antimicrobial agents like antibiotics and disinfectants. Antibiotic treatment is currently the most widely used therapy for $P$. aeruginosa infections. Consequently, antibiotic resistance has been observed in some $P$. aeruginosa strains. So strategies to address this have focused on the use of bacteriophage mixes with or without the antibiotics, ${ }^{[35,36]}$ using the surface modification with copper ${ }^{[37]}$ and silver ${ }^{[37,38]}$ or graphene oxide, ${ }^{[39]}$ to improve antibacterial effect. Copper and silver ions

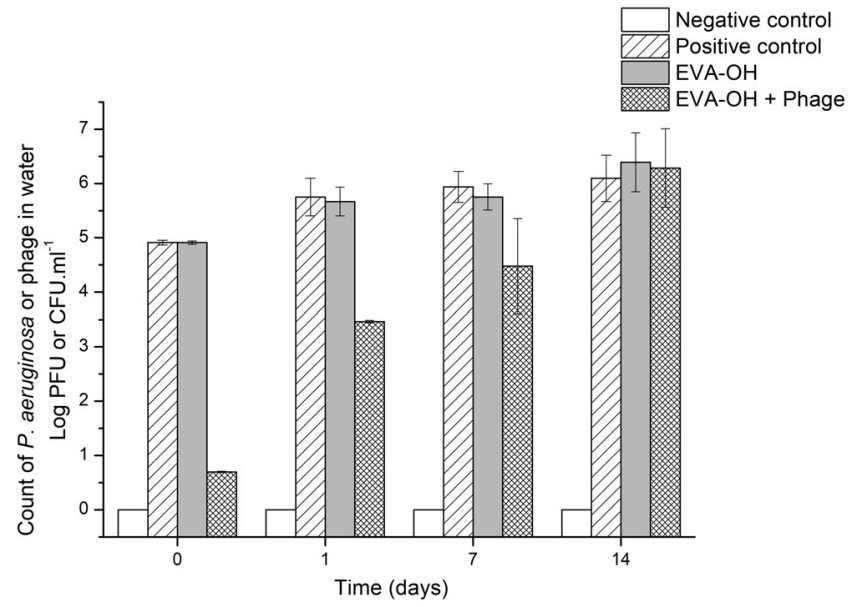

FI G U RE 5 Pseudomonas aeruginosa ( $\log \mathrm{CFU} / \mathrm{ml})$ and DP1 bacteriophages $(\log \mathrm{PFU} / \mathrm{ml})$ counts after $0,1,7$, and 14 days of assay carried out for testing the anti-P. aeruginosa activity of EVA$\mathrm{OH}$ copolymers used as cap seal containing immobilized DP1 phages inside mineral water bottles. Containing the virus ("Bottle with EVA-OH"), without the virus but with the bacteria ("Positive control bottle"), and without the virus and bacteria ("Negative control bottle")

concentrations tested (0.1-0.8 mg/l) achieved more than $99.999 \%$ reduction of $P$. aeruginosa, in 6,12 , and $96 \mathrm{~h}$, respectively. ${ }^{[37,38]}$ But combination of copper and silver ions exhibited a synergistic effect against $P$. aeruginosa. ${ }^{[37]}$

Pseudomonas aeruginosa cells increased up to $1.75 \mathrm{log}$ $\mathrm{CFU} / \mathrm{ml}$ over 14-day incubation period inside bottles containing the polymer without DP1 phages ("positive control bottle"). Thus, EVA copolymers containing attached DP1 phages, mainly EVA-OH, seem to be a viable alternative to reduce $P$. aeruginosa into mineral water bottles. This is an approach that needs attention due to the effects of low toxicity. ${ }^{[36]}$ However, others studies are necessary for validation of the use of this seal caps of water bottles, regarding the applications in the beverage industries.

\section{CONCLUSION}

According to our results, it was possible to produce a nontoxic and more hydrophilic EVA copolymer with antimicrobial action against $P$. aeruginosa. Moreover, to the best of our knowledge, there are no reports in the literature which investigate EVA-OH copolymers with immobilized phages, which characterizes the innovative characteristic of this research.

Furthermore, the EVA-OH copolymers used as seal caps of plastic bottles for mineral water were able to reduce the counts of the $P$. aeruginosa present in mineral water bottles, indicating a possible control measure for controlling the eventual contamination of mineral 
water by $P$. aeruginosa. However, other experiments are necessary in order to test new conditions able to reduce the time of action of the DP1 phage against $P$. aeruginosa, such as virus concentration and water temperature. The proposed approach is promising as it uses a polymer that is already used in the manufacturing of bottle seals.

\section{ACKNOWLEDGMENTS}

The authors thank CAPES for scholarships to Cesar H. Wanke and Junia Novello. CNPq-National Council for Scientific and Technological Development, Brazil for financial support (grant numbers 308241/2015-0 and 306086/2018-2). Sanna Sillankorva acknowledges funding from the European Union's Horizon 2020 research and innovation programme (grant number 713640).

\section{ORCID}

\section{Otávio Bianchi (iD https://orcid.org/0000-0001-7493-8163}

\section{REFERENCES}

[1] E. N. Kokkinakis, G. A. Fragkiadakis, A. N. Kokkinaki, Food Control 2008, 19, 957.

[2] D. Venieri, A. Vantarakis, G. Komninou, M. Papapetropoulou, Int. J. Food Microbiol. 2006, 107, 68.

[3] D. W. Warburton, Can. J. Microbiol. 1993, 39, 158.

[4] A. Casanovas-Massana, F. Lucena, A. R. Blanch, J. Microbiol. Methods 2010, 81, 1.

[5] M. F. Falcone-Dias, I. Vaz-Moreira, C. M. Manaia, Water Res. 2012, 46, 3612.

[6] Brasil. in $R D C N^{\circ} 275$ (Ed: Anvisa), Anvisa, Brasília 2005.

[7] Directive, E.C. in EUR-Lex-31980L0777 (Ed: European Community) 1980.

[8] F. A. Rosenberg, H. H. Duquino, Toxic. Assess. 1989, 4, 281.

[9] C. Sánchez-Carrillo, B. Padilla, M. Marín, M. Rivera, E. Cercenado, D. Vigil, M. Sánchez-Luna, E. Bouza, Am. J. Infect. Control 2009, 37, 150.

[10] U. Komor, P. Bielecki, H. Loessner, M. Rohde, K. Wolf, K. Westphal, S. Weiss, S. Häussler, Microbes and Infection 2012, 14, 951.

[11] H. Leclerc, A. Moreau, FEMS Microbiol. Rev. 2002, 26, 207.

[12] D. H. Duckworth, P. A. Gulig, BioDrugs 2002, 16, 57.

[13] A. G. de Melo, S. Levesque, S. Moineau, Curr. Opin. Biotechnol. 2018, 49, 185.

[14] S. Sillankorva, P. Neubauer, J. Azeredo, BMC Biotechnol. 2008, 8,1 .

[15] L. Y. Brovko, H. Anany, M. Griffiths, W. Advances in Food and Nutrition Research 2012, 67, 241.

[16] H. A. Pearson, G. S. Sahukhal, M. O. Elasri, M. W. Urban, Biomacromolecules 2013, 14, 1257.

[17] C. Wang, D. Sauvageau, A. Elias, ACS Appl. Mater. Interfaces 2016, 8, 1128.

[18] H. Anany, W. Chen, R. Pelton, M. W. Griffiths, Appl. Environ. Microbiol. 2011, 77, 6379.

[19] A. Díaz, L. J. Del Valle, N. Rodrigo, M. T. Casas, G. Chumburidze, R. Katsarava, J. Puiggalí, Fibers 2018, 6, 33.
[20] U. Puapermpoonsiri, J. Spencer, C. F. van der Walle, Eur. J. Pharm. Biopharm. 2009, 72, 26.

[21] World Health Organization, Guidelines for Drinking-water Quality, Switzerland, 2011.

[22] CFR- Code of Federal Regulations, C. o. F.; U.S. Food and Drug Administration: 2019, 21, 3.

[23] A. F. Osman, M. Fitri, T. F, M. Rakibuddin, F. Hashim, S. A. T. Tuan Johari, R. Ananthakrishnan, R. Ramli, Mater. Sci. Eng. C 2017, 74, 194.

[24] A. F. Osman, A. M. Alakrach, H. Kalo, W. N. W. Azmi, F. Hashim, RSC Adv. 2015, 5, 31485.

[25] K. Bhunia, S. S. Sablani, J. Tang, B. Rasco, Compr. Rev. Food Sci. Food Saf. 2013, 12, 523.

[26] M. M. Paradinha, F. T. Gonzalez Dias, C. H. Wanke, J. C. Lima Novello, E. C. Tondo, J. Nardi Martins, O. Bianchi, J. Appl. Polym. Sci. 2017, 134, 44558.

[27] L. D. Agnol, F. T. G. Dias, N. F. Nicoletti, D. Marinowic, S. Moura e Silva, A. Marcos-Fernandez, A. Falavigna, O. Bianchi, J. Biomater. Appl. 2019, 34, 673.

[28] D. K. Owens, R. C. Wendt, J. Appl. Polym. Sci. 1969, 13, 1741.

[29] D. Pires, S. Sillankorva, A. Faustino, J. Azeredo, Res. Microbiol. 2011, 162, 798.

[30] E. Marie, Y. Chevalier, N. Issartel, F. Eydoux, L. Germanaud, P. Flores, Macromolecules 2001, 34, 5838

[31] M. Tang, J. Hou, L. Lei, X. Liu, S. Guo, Z. Wang, K. Chen, Int. J. Pharm. 2010, 400, 66.

[32] F. C. N. do Amaral, J. R. Ernzen, R. Fiorio, J. D. N. Martins, F. T. G. Dias, R. Avolio, O. Bianchi, Polym. Eng. Sci. 2018, $58,335$.

[33] J. Kong, S. Yu, Acta Biochim. Biophys. Sin. 2007, 39, 549.

[34] K. K. Mokwena, J. Tang, Crit. Rev. Food Sci. Nutr. 2012, 52,640 .

[35] Y. Lin, R. Y. K. Chang, W. J. Britton, S. Morales, E. Kutter, H.K. Chan, Int. J. Pharm. 2018, 551, 158.

[36] S. Trend, A. M. Fonceca, W. G. Ditcham, A. Kicic, A. Cf, J. Cystic Fibrosis 2017, 16, 663.

[37] V. JankauskaitL, A. VitkauskienL, A. Lazauskas, J. Baltrusaitis, I. ProsyLevas, M. AndruleviLius, Int. J. Pharm. 2016, 511, 90.

[38] R. B. Domínguez-Espíndola, C. Bruguera-Casamada, S. SilvaMartínez, R. M. Araujo, E. Brillas, I. Sirés, Sep. Purif. Technol. 2019, 208, 83 .

[39] A. N. Mohan, B. Manoj, Mater. Chem. Phys. 2019, 232, 137.

\section{SUPPORTING INFORMATION}

Additional supporting information may be found online in the Supporting Information section at the end of this article.

How to cite this article: Novello J, Sillankorva S, Pires P, et al. Inactivation of Pseudomonas aeruginosa in mineral water by DP1 bacteriophage immobilized on ethylene-vinyl acetate copolymer used as seal caps of plastic bottles. J Appl Polym Sci. 2020;137:e49009. https://doi.org/10.1002/app. 49009 